О.Н. МИнУшкин, д.м.н., профессор, Центральная государственная медицинская академия Управления делами Президента РФ, Москва

\title{
ФУНКЦИОНАЛЬНЫЙ ЗАПОР
}

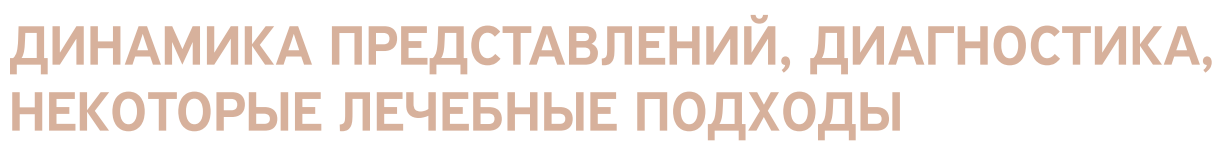

В работе приводятся данные о функциональных запорах (ФЗ): определение (в том числе и последнего консенсуса - Рим IV), эпидемиология, диагностика, общие подходы к лечению и результаты использования препарата стимулирующего действия Слабилен, производимого отечественной фирмой «Верофарм». Препарат использован у 30 больных, положительный эффект составил 90\%. Достоинством препарата является двойной механизм действия: стимулирующий, осмотический. Патологические эффекты не зафиксированы.

Ключевые слова: запор, функциональный запор, слабительные средства, пикосульфат натрия, Слабилен.

O.N. MINUSHKIN, MD, Prof., Central State Medical Academy of Department of Presidential Affairs of RF, Moscow FUNCTIONAL CONSTIPATION, DYNAMICS OF PRESENTATIONS, DIAGNOSTICS, INDIVIDUAL APPROACHES TO THE TREATMENT The article presents data on functional constipation (FC): the definition (including the one of the last consensus - Rome IV), epidemiology, diagnostics, general approaches to the treatment and the results of using the stimulant drug Slabilen manufactured by the domestic firm Veropharm. 30 patients received the drug, and the positive effect accounted for $90 \%$. The advantage of the drug is a double mechanism action: stimulating and osmotic. No pathological effects have been detected.

Keywords: constipation, functional constipation, laxatives, picosulfate sodium, Slabilen.

апором считают хроническую (более 48 ч) задержку опорожнения кишечника. Более широкая трактовка понятия позволяет отнести к запору также затруднение дефекации (при сохранении нормальной периодичности стула) [1].

\section{ЭПИДЕМИОЛОГИЯ}

По данным различных источников, запором страдают от 2 до 27\% населения всех социальных и возрастных групп. Среди пациентов превалируют женщины, жители городов, не занятые физической деятельностью. Распространенность запоров увеличивается с возрастом [2-4]. Однако истинное состояние ситуации остается за пределами точного знания, так как на него оказывают влияние психологический фактор, деликатность жалоб, нежелание отдельных больных сообщать (в том числе и врачу) свои ощущения, связанные с проявлениями запора [1, 5]. В РФ статистика, определяющая распространенность запора, отсутствует, но средние показатели, публикуемые в различных отчетах, аналогичны представленным.

С практической и патогенетической точек зрения различают следующие формы запоров:

1. Органический, вызванный механической обструкцией толстой кишки (опухоль, стриктура, сдавление извне, аномалии развития).

2. Функциональный, вызванный расстройствами функций кишечника.

3. Проктогенный, обусловленный снижением (утратой) рефлекса на дефекацию.

Это важно, так как такое деление четко определяет лечебный подход. Терапевты и гастроэнтерологи в основ- ном занимаются функциональными запорами, чему и будет посвящено настоящее сообщение.

Определение функциональных запоров было утверждено в согласительном документе «Рим II: Мультинациональный консенсус по функциональным желудочно-кишечным расстройствам», рубрика С3, где он характеризуется как «Персистирующая затрудненная, редкая или кажущаяся неполной дефекация», которая фиксируется на протяжении, по крайней мере, 3 мес. при общей продолжительности не менее 6 мес. (необязательно непрерывных, при этом самостоятельный стул редко возникает без использования слабительных средств).

Консенсус Рим III, рассматривая хронический Ф3, отмечает, что патогенез ФЗ не связан с известными генетическими, структурными и органическими изменениями кишечника, но должны присутствовать два или более из числа следующих признаков:

- Редкая эвакуация содержимого кишечника (менее 3 дефекаций в неделю).

- Отхождение при дефекации малого количества кала (менее 35 г/сут).

- Кал должен быть сухим и плотным, травмирующим задний проход.

- Ощущение чувства «блока» в прямой кишке (аноректальная обструкция).

- Эвакуация кала сопровождается натуживанием (не менее 25\% времени дефекации).

И наконец, консенсус Рим IV определяет ФЗ как функциональное кишечное расстройство, при котором доминируют симптомы затрудненной, нечастой и неполной дефекации. Пациенты с ФЗ не должны иметь критериев синдрома раздраженного кишечника (СРК), хотя абдоми- 
нальная боль и/или вздутие могут присутствовать, но они не являются доминирующими. Начало симптомов должно наблюдаться за 6 мес. до установления диагноза, и они должны присутствовать во время последних 3 мес.

Рассматривая динамику определений функционального запора, следует признать, что определение Рим IV максимально точно дает не только определение, но и исключает возможность рассматривать в этой рубрике другие формы ФЗ (вариант СРК с запором), что нередко делалось прежде.

Классификационно Ф3 отнесен в рубрику С3 (кишечные расстройства), пункт 2 - функциональный запор (С3.2).

\section{ДИАГНОСТИКА}

Главным постулатом Римского консенсуса IV является определение функциональных заболеваний желудочнокишечного тракта (ЖКТ): «...функциональные расстройства ЖКТ являют собой нарушение кишечно-мозгового взаимодействия». Это группа расстройств, классификация которых основана на кишечных симптомах, связанных между собой в любых сочетаниях: нарушение моторики, висцеральная гиперчувствительность, иммунная дисфункция, изменение микрофлоры кишечника, нарушение работы ЦНС.

\section{Консенсус Рим IV определяет ФЗ как функциональное кишечное расстройство, при котором доминируют симптомы затрудненной, нечастой и неполной дефекации. Пациенты с ФЗ не должны иметь критериев синдрома раздраженного кишечника, хотя абдоминальная боль и/или вздутие могут присутствовать, но они не являются доминирующими}

Вторым важнейшим компонентом диагностики является определение Ф3, данное консенсусом Рим IV: «...Ф3 функциональное кишечное расстройство, при котором доминируют симптомы затрудненной, нечастой или неполной дефекации». Если мы впервые встречаемся с этой клинической ситуацией, учитывая разнообразие причин и механизмов развития, алгоритм диагностики должен включать следующие этапы $[1,6]$.

\section{1-й этап:}

- Оценка клинических данных (исключение признаков запорного варианта (РК).

- Рентгенологическое исследование кишечника, позволяющее оценить анатомическое состояние толстой кишки (либо ее нормальное строение, либо аномалии положения, идиопатический мегаколон, опухоли, стриктуры, спаечная болезнь).

\section{2-й этап:}

- Колоноскопия с биопсией слизистой оболочки для уточнения (или исключения структурных изменений).

- Оценка состояния моторики кишечника и толстой кишки (в частности).

\section{3-й этап:}

- Специальные методы исследования: электромиография, состояние запирательного аппарата прямой кишки, анальная манометрия, исследование микробного статуса, короткоцепочечных жирных кислот (КЖК) в кале, изучение электролитного баланса, изучение висцеральной гиперчувствительности с помощью баростата, позитронно-эмиссионной томографии (ПЭТ), функциональной магнитно-резонансной томографии (фМРТ).

По результатам этих исследований диагноз функционального запора может быть идентифицирован и охарактеризован (уточнен патогенез, способствующие факторы, тяжесть клинической ситуации, выбраны патогенетически обоснованные препараты, определена их суточная доза и продолжительность лечения).

Пример формулировки диагноза:

Ф3, обусловленный замедленным кишечным транзитом (первичная дисфункция гладкой мускулатуры), висцеральная гиперчувствительность, дисбактериоз толстой кишки II степени тяжести, иммунная дисрегуляция (снижение активности гуморального иммунного ответа), выраженность запора умеренная.

\section{ЛЕЧЕНИЕ}

\section{А. Общие принципы лечения Ф3:}

- после уточнения характера питания проводится коррекция диеты (изменяется объем и характер питания, регулируется водный баланс),

- коррекция образа жизни, в основном физической активности (в соответствии с возрастом и активностью кишечника),

- коррекция негативных медикаментозных влияний (отмена, изменение дозы, замена на препараты другой патогенетической группы),

- нормализация моторной функции толстой кишки (прокинетики при гипокинезии или спазмолитики при гиперкинезии толстой кишки),

- применение слабительных средств.

Использование слабительных средств при запорах далеко не простое дело, а решение об их использовании должно быть не началом фармакотерапии, а венчать конец выбора. Само же лечение следует проводить только под тщательным наблюдением терапевта или гастроэнтеролога.

\section{Б. Говоря о диетах, следует помнить, что причинами фор- мирования ФЗ у детей раннего возраста являются:}

перевод на искусственное вскармливание;

- формирование пищевой аллергии (прежде всего к белкам коровьего молока), нередко эта причина сопровождает и взрослого;

- императивное воспитание туалетных навыков (у детей 1-2 лет);

- болезненность дефекаций с развитием «болезни горшка»; - начало посещения детского учреждения;

- отсутствие «комфортных» условий для осуществления дефекации. 
Эти положения нужно помнить и рассматривать их как важные при выборе лечения запоров у детей.

Диетические рекомендации пациенту с запорами строятся в зависимости от моторной функции толстой кишки. Так, при гипомоторной дискинезии рацион формируется по типу «шлаковой» нагрузки. Освобождению кишечника способствуют овощи, фрукты, ягоды, преимущественно сырые, не менее 200 г/сут, чернослив или курага (8-12 ягод), бананы и яблоки, растительное масло (оливковое, кукурузное) - 1-2 ст. л. натощак (лучше размешать в кефире и принимать на ночь). Гречневая, овсяная, ячневая, перловая каши, мед - 1 ст. л. 2-3 раза в сутки, пшеничные отруби включены в специальные сорта хлеба «Здоровье», «Барвихинский», «Докторский». Количество жидкости следует увеличить до 1,5-2 л/сут. Целесообразно выпивать 1-2 стакана холодной воды (фруктового сока) утром натощак с добавлением 1 ст. л. меда или ксилита.

Из рациона исключить рисовую, манную каши, макароны, вермишель, картофельное пюре, кисели, поскольку эти продукты тормозят опорожнение кишечника.

Вне зависимости от преобладающего типа моторики толстой кишки в рационе питания используют пищевые волокна (отруби, микрокристаллическую целлюлозу, мукофальк (псиллиум) - семенную кожуру подорожника, морскую капусту, биологически активные добавки с высоким содержанием растворимых и нерастворимых волокон). Обязательным условием применения пищевых волокон является соблюдение увеличенного водного баланса, так как они адсорбируют воду, увеличивают бактериальную флору, повышают массу фекалий и изменяют миоэлектрическую активность кишечника, что приведет в равновесие пропульсивные и тонические сокращения мускулатуры толстой кишки. При разрушении пищевых волокон увеличивается образование короткоцепочечных жирных кислот, которые используются как трофический субстрат для энтероцитов (ацетат, пропионат). У пожилых и старых пациентов при наличии сердечной недостаточности эти рекомендации следует использовать с осторожностью. При гипермоторной дискинезии диета более щадящая. Овощи дают в отварном виде, большое внимание уделяется растительным жирам. Пшеничные отруби назначаются в постепенно повышающихся дозах с отработкой оптимального количества, поддерживающего терапевтический эффект.

В образе жизни важно отсутствие утренней спешки, прием «объемного» завтрака, комфортабельный удобный туалет, удобная поза в туалете (с подтянутыми коленями, ноги на маленькой скамеечке), утренняя гимнастика (движение Вальсальвы, имитация езды на велосипеде, самомассаж живота).

\section{В. Лекарственная терапия направлена в первую очередь на регуляцию моторики.}

При этом следует помнить, что в основе развития запора могут лежать лекарственные препараты, тормозящие моторику (холинолитики, спазмолитики с широким спектром действия, блокаторы гистаминовых рецепторов и др.). В этом плане следует тщательно собрать лекарственный анамнез и от каких-то групп препаратов следу- ет отказаться, а какие-то заменить или снизить дозу. После того как проведена коррекция исходной фармакотерапии (вторично влияющей на моторику толстой кишки) и установлен тип расстройства моторики (гипотония, гипертония, расстройство моторики по смешанному типу), назначают «регуляторы моторики» ЖКТ.

\section{Использование слабительных средств при запорах - далеко не простое дело, а решение об их использовании должно быть не началом фармакотерапии, а венчать конец выбора. Само же лечение следует проводить только под тщательным наблюдением терапевта или гастроэнтеролога}

В разные периоды мы использовали Мотилиум, Ганатон, Дебридат, Итомед, Тримедат. Все они относятся к группе «регуляторов моторики», а изученные группы больных имели «замедленный транзит» с преобладанием гипотонии толстой кишки. Общее количество больных - 120 (по 30 в каждой группе). Сравнительной оценки мы не проводили, но общая эффективность составила 70-90\%. Все эти препараты относятся к группе «рецепторных», и все они при длительном лечении (1,5-2 месяца) характеризуются «ускользанием терапевтического эффекта», что требует либо увеличения дозы препарата, либо замены препарата с иным механизмом действия, либо комбинированного лечения.

\section{ИСПОЛЬЗОВАНИЕ СЛАБИТЕЛЬНЫХ СРЕДСТВ}

Все слабительные средства можно разделить на три основные группы.

\section{1. Увеличивающие объем кишечного содержимого: \\ пищевые волокна, \\ - гидрофильные коллоиды (макроголи),}

осмотические: олигосахариды (лактитол, лактулоза, дюфалак); спирты (сорбит, маннитол, глицерил); солевые слабительные (магнезия, глауберова соль и др).

\section{2. Стимулирующие:}

- антрагликозиды (препараты сенны, крушины, ревеня), - производные дифенилметана (бесакодил, дульколакс), - пикосульфат натрия (Гутталакс, Слабилен, ОАО «Верофарм», Россия).

\section{3. Размягчающие фекалии (вазелиновое и другие мине- ральные масла).}

У каждой из указанных групп препаратов есть свои достоинства и недостатки. Для каждой группы должны быть определены больные по характеру расстройства моторики, возрасту, сочетанной патологии, характеру расстройства микрофлоры и др.

Так, гидрофильные коллоиды обладают умеренно выраженным осмотическим действием и увеличивают объем кишечного содержимого. Их недостаток - медленно развивающийся эффект, выраженная гипотония кишки. Препараты данной группы не показаны пациентам с проктогенными запорами. 
Осмотические слабительные (сорбит, маннитол, глицерин) и солевые действуют на уровне тонкой кишки и способствуют большому выделению в просвет кишки жидкости, при этом возможна диарея, тканевая дегидратация и потеря электролитов. В настоящее время они используются в комплексной подготовке кишечника к исследованию. Группа «стимулирующих» обладает быстрым эффектом, иногда непредсказуемым, быстрым привыканием и большими издержками, особенно у больных сердечно-сосудистой патологией. Имея ограниченный срок использования, многие препараты требуют тщательного врачебного контроля. Так, метаболиты препарата сенны при длительном применении накапливаются в слизистой оболочке кишечника, нейронах ганглионарных сплетений, что ведет к дегенеративным изменениям гладкой мускулатуры с развитием «инертной толстой кишки». Метаболиты антрагликозидов гепато- и нефротоксичны, обладают мутагенным действием и не должны использоваться длительно, а тем более постоянно.

Сложности использования слабительных средств заключаются в том, что лечение ими требует тщательного контроля, подбора эффективной дозы, своевременного изменения ее или замены. Недостаточный контроль за лечением слабительными может привести:

к слабому (недостаточному) эффекту;

- чрезмерному эффекту (неуправляемый стул);

- ускользанию эффекта (возврат запоров) и др.

Это ведет к тому, что начинается новый цикл работы с больным (иногда повторное обследование; назначение нового препарата с оценкой эффекта и подбором минимально эффективной дозы, использование сочетанного: регулятор моторики - слабительное; комбинация слабительных с разным механизмом действия). Из группы «стимулирующих» слабительных хотелось бы поделиться опытом использования отечественного препарата Слабилен (ОАО «Верофарм», Россия). Действующим веществом препарата Слабилен является пикосульфат натрия, который путем гидролиза под влиянием сульфатирующих кишечных микроорганизмов переходит в действующую форму, возбуждая нервные структуры кишечной стенки, в результате чего ускоряется продвижение кишечного содержимого. Вторым механизмом действия препарата является уменьшение всасывания электролитов и воды (осмотический эффект).

Слабительный эффект наступает через 6-12 ч после приема. Препарат не всасывается из желудочно-кишечного тракта, не подвергается метаболизму в печени, ускоряет транзит (купирует запор) и формирует ощущение полного опорожнения. Препарат принимается однократно, на ночь. Эффективная доза подбирается индивидуально в зависимости от возраста, продолжительности и выраженности запоров, начальной дозой может быть 10-20 капель, растворенных в воде; при необходимости доза может быть увеличена до 30 капель. Препарат выпускается и в таблетках - 5 мг (суточная доза 5-10 мг, однократно, на ночь).

Наш опыт применение препарата Слабилен составляет группа пациентов, из которых 30 человек - с функци- ональными запорами, интенсивность запора умеренная у 20 больных, выраженная - у 10, преобладали женщины в возрасте $45 \pm 7,5$ года. Продолжительность запоров в среднем $10 \pm$ 4,6 года, в анамнезе больные использовали препараты разных групп (регуляторы моторики, осмотические слабительные, сочетанную терапию) с нестабильным эффектом, с феноменом «ускользания», требуя постоянной коррекции дозы. Нередко больные, утратив послабляющий эффект препарата, прекращали лечение.

Уточнив патогенез функционального запора, мы назначали Слабилен. Исходной дозой были 5 мг - при умеренном запоре или 10 мг - при выраженном. Эффект купирования запора наступал быстро (при достаточной дозе) 1-2 дня. Лучше препарат титруется в каплях. При подборе достаточной дозы происходил перерасчет ее на таблетки (это удобнее). Общая эффективность лечения составила 90,3\%. Продолжительность лечения 30 дней. Эффект последействия сохранялся на протяжении 2 нед., зависел от продолжительности запора (у больных с меньшей продолжительностью запоров он был более длительным). Побочных эффектов зарегистрировано не было. Препарат Слабилен оценен нами как весьма эффективное слабительное. При коротком анамнезе запоров терапия может быть начата с использования препарата Слабилен; при длительном анамнезе - с использования регуляторов моторики и добавлением стимулирующих слабительных при недостаточной эффективности. Достоинством Слабилена является двойной механизм действия: стимуляция перистальтики и осмотическое действие, что значительно расширяет показания к его использованию.

\section{ВЫводы}

1. Слабилен (пикосульфат натрия) является эффективным слабительным при ФЗ.

2. Имея 2 формы (капли и таблетки), легко титруется эффективная минимальная доза.

3. Исходной дозой Слабилена при умеренном запоре является 5 мг; при выраженном запоре 10 мг.

4. Побочных эффектов при 30-дневном лечении отмечено не было.

5. Эффект последействия составил в среднем 2 нед. (продолжительность зависела от длительности запора).

\section{ЛИТЕРАТУРА}

1. Минушкин О.Н. Хронический запор (определение, эпидемиология диагностика): современная медикаментозная терапия. Медицинский совет, 2015, 13: 100-105.

2. Garrigues $\vee$ et al. Prevalence of constipation agreement among several criteria and evaluation of the diagnostic accuracy of qualifying symptoms and self-reported definition in population in Spain. Am J Epidemiol, 2004, 159: 520-526.

3. Zembo A Camilleri M. Chronic constipation. N Engl J Med, 2003, 349: 1360-1368.

4. Pare $P$ et al. An epidemiological survey of constipation in Canada definitions rates demographics and predictors of health care seeking. Am J gastroenterol, 2001, 96: 3130-3137.

5. Пасечников В.Д. Функциональный запор, обусловленный замедленным транзитом кишечного содержимого. Фарматека, 2003, 10: 16-22.

6. Елизаветина Г.А., Минушкин О.Н. Запоры и некоторые принципы их лечения. Клиническая фармакология и терапия, 1997, 6: 51-53. 